\title{
Erratum to: Long-distance dispersal of a wolf, Canis lupus, in northwestern Europe
}

\author{
Liselotte Wesley Andersen ${ }^{1}$. Verena Harms ${ }^{2}$ - Romolo Caniglia ${ }^{3}$. \\ Sylwia D. Czarnomska ${ }^{4}$ - Elena Fabbri ${ }^{3}$ - Bogumila Jęrzejewska ${ }^{4}$. \\ Gesa Kluth $^{5}$ - Aksel Bo Madsen ${ }^{1}$ - Carsten Nowak ${ }^{2}$ - Cino Pertoldi ${ }^{6,7}$. \\ Ettore Randi $^{3,6} \cdot$ Ilka Reinhardt ${ }^{5}$. Astrid Vik Stronen ${ }^{6}$
}

Published online: 26 May 2015

(C) Mammal Research Institute, Polish Academy of Sciences, Białowieża, Poland 2015

\section{Erratum to: Mamm Res (2015) 60:163-168 \\ DOI 10.1007/s13364-015-0220-6}

In the initial article, page 167, last sentence of the last paragraph in the body text (above acknowledgment section), the reference citation for "Ciucci et al. 2009" had been misspelled and the reference had been excluded from the reference list.

The published version currently reads as:

"Identical trends of an ongoing rapid dispersal of wolves (Giucci et al. 2009; Duchamp et al. 2012) are observed in other western and central European countries including France and Germany."

The online version of the original article can be found at http://dx.doi.org/ 10.1007/s13364-015-0220-6.

Liselotte Wesley Andersen

lwa@bios.au.dk

1 Department of Bioscience, Aarhus University, Kalø, Grenåvej 14, 8410 Rønde, Denmark

2 Senckenberg Research Institute and Natural History Museum, Frankfurt, Clamecystraße. 12, 63571 Gelnhausen, Germany

3 Laboratorio di Genetica, ISPRA, 40064 Ozzano dell'Emilia, (BO), Italy

4 Mammal Research Institute Polish Academy of Science, Waszkiewicza 1, 17-230 Białowieża, Poland

5 LUPUS - German Institute for Wolf Monitoring and Research, Dorfstraße 20, 02979 Spreewitz, Germany

6 Department of Chemistry and Bioscience, Aalborg University, Frederik Bajers Vej 7H, DK-9220 Aalborg Øst, Denmark

7 Aalborg Zoo, Mølleparkvej 63, DK-9000 Aalborg, Denmark
The revised sentence is presented here:

"Identical trends of an ongoing rapid dispersal of wolves (Ciucci et al. 2009; Duchamp et al. 2012) are observed in other western and central European countries including France and Germany."

Furthermore, the complete reference entry for Ciucci et al. (2009) is presented in this paper.

We regret the error and apologize for any inconvenience caused.

\section{References}

Ciucci P, Reggioni W, Maiorano L, Boitani L (2009) Long-distance dispersal of a rescued wolf from the Northern Apennines to the Western Alps. J Wildl Manag 73(8): 1300-1306 